\title{
UM ESTUDO SOBRE A VARIAÇÃO DO USO DE “NÓS” E “A GENTE” NA CIDADE DE LUZIÂNIA - GO
}

\author{
ANALYSIS OF THE USE OF "NÓS" AND "A GENTE IN LUZIÂNIA CITY - GO
}

LIMA, Antonio Elton de ${ }^{1}$

\section{RESUMO}

Este artigo consiste em observar a variação, no português brasileiro, dos pronomes de primeira pessoa nós e a gente na posição de sujeito e complemento, utilizando como variáveis fatores sociais como sexo, faixa etária, escolaridade e posição sintática, pelos moradores da cidade de Luziânia, Goiás. A pesquisa foi realizada com base nos princípios metodológicos da Sociolinguística Laboviana. Com os resultados não se constatou uma mudança em curso propriamente dita, mas uma variação linguística com a preferência pelo uso da forma inovadora a gente, o fator extralinguístico sexo não foi relevante para a pesquisa à medida que a preferência por umas das variantes entre homens e mulheres não tiveram diferenças relevantes. Entretanto os fatores faixa etária, escolarização e posição sintática foram os que mais demonstraram uso de a gente, refletindo uma mudança diacrônica do pronome nós para o pronome a gente.

PALAVRAS-CHAVE: A gente; Nós; Variação.

\section{ABSTRACT}

This article consists of observing the variation of the first-person pronouns "NÓS" and "A GENTE in Brazilian Portuguese, in the position of subject and complement, using for variables social factors such as gender, age, schooling and syntactic position, from Luziania's residents, Goiás. The research was carried out based on the methodological principles of Labovian Sociolinguistics. With the results, there wasn't found a change, but a linguistic variation on the preference for the use of the innovative way "the people". The extralinguistic factor gender was not relevant for the research as the preference for one of the variants between men and women had no significant differences. However the factors age, schooling and syntactic position were the ones that demonstrated the most use of "the people", reflecting a diachronic change from the pronoun "we" to the pronoun "the people".

Keywords: Nós; A gente; Variation.

'Graduando do Curso de Letras da Universidade de Brasília (UnB), eltonlima2013@gmail.com; Orientado pelo prof. Dr. Paulo Medeiros Junior, LIP UnB. 


\section{INTRODUÇÃO}

A linguagem evoluiu com o ser humano. Em algum ponto da evolução, o cérebro da espécie ganhou um formato especial, conexões sinápticas foram constituídas, e a linguagem aflorou entre os homo-sapiens. Assim como se observam saltos de evolução biologica na espécie humana, pode-se constatar que a linguagem, em suas bases, tem se apresentado em constante processo de evolução.

Falamos línguas diferenttes ao redor do mundo e, embora se diga que essas línguas em essência apresentam uma base comum (Chomsky 1986), há diferenças interessantes entre elas.

Os falantes de inglês, por exemplo, conhecem e seguem uma regra básica em sua gramática mental: não é possível deixar a posição de sujeito vazia na sentença. Assim, sentenças como (1) são impossíveis em Inglês:

(1) a. *rains.

b. *worked yesterday.

Essas sentenças na língua inglesa precisam ter as posições de sujeito preenchidas; apenas as frases em (2) são possíveis

(2) a. It rains

b. He / We / I worked yesterday.

Os falantes do português europeu, por exemplo, têm outra regra mental na gramática de sua língua; e a seguem estritamente: sempre é possível deixar a posição de sujeito vazia. Dessa forma, sentenças como as que aparecem em (3) são possíveis:

(3) a. Chove.

b. Pedalava no parque.

c. Fazeis bem em obedecer. 
Já o português falado no Brasil é uma língua que parece estar no meio do caminho. É possível deixar a posição de sujeito vazia em certos contextos, como em (4), mas não em outros, como (5):

(4) Fomos ao cinema.

(5) \#Pedalava no parque.

A sentença em (5) só funciona em português do Brasil se o contexto maior apontar a referência para o sujeito:

(6) João era uma pessoa diferente antes. Corria, pedalava no parque. Hoje desistiu de tudo.

Internamente a uma mesma língua, falamos de maneiras diferentes para expressar as mesmas ideias, empregamos expressões e organizamos a línguagem de uma maneira a refletir estilo pessoal, hábitos linguísticos de nossa família ou de uma comunidade de fala em que nos inserimos.

De uma região para a outra em um país como o Brasil, é possível registrar falares diferenciados; é possível observar registros de uso da língua distintos entre uma e outra camada da sociedade, ou mesmo observar formatos opostos para uma língua em uma comunidade em estágios diferentes de sua história. A esse fenômeno damos o nome de variação linguística, alterações observadas nas línguas que, como já dissemos, podem ser compreendidas através de relações históricas, regionais ou sociais. Este trabalho põe em foco a linguagem de um ponto de vista sincrônico, não deixando de se ater a questões diacrônicas, olhando para fatores como a variação social.

No quesito histórico, a língua passa por diversas mudanças de acordo com as necessidades dos falantes; por não ser algo fechado, o sistema linguístico se adapta, por exemplo, às condições de entendimento de cada geração, os rearranjos são inevitáveis e acabam contribuindo para a mudança do modo de falar de gerações posteriores.

Este trabalho tem como objetivo analisar os contextos de uso das variantes nós e a gente, empregadas para designar a $1^{\underline{a}}$ pessoa do plural pelos falantes de 
português do Brasil, os fatores internos e externos à língua, o ambiente que as favorece, e se há transitoriedade no fenômeno ou se é algo permanente. A tese defendida consiste na afirmação de uma mudança em curso, principalmente na fala, porque cada vez menos ouvimos a variante consagrada nós nas conversas não monitoradas, como também em ambientes menos formais, ficando seu uso quase restrito à escrita.

Esta pesquisa visa investigar as características do sistema linguístico que favorecem a aplicação de uma ou de outra forma, buscando determinar quais fatores e quais circunstâncias determinam o uso tendo como base o controle de variáveis como gênero, faixa etária, escolarização e posição sintática, elementos cuja análise visa determinar a frequência e o condicionamento de uso de cada variante.

A pesquisa justifica-se pela necessidade de investigar o fenômeno que perpassa a primeira pessoa do plural na cidade de Luziânia, interior do estado de Goiás no entorno de Brasília, município com população estimada para 2016 de acordo com IBGE em 196.864 pessoas, quinto município mais populoso do estado, que ainda conserva ares de cidade do interior, com a interação de casarões antigos e construções verticais modernas como shoppings, apartamentos, lojas, etc.

Nossa pesquisa foi realizada através de entrevista com moradores da cidade de Luziânia através de questionário com duas alternativas levando o entrevistado a responder usando umas das variáveis, nós ou a gente, seja em posição de sujeito ou complemento. Os informantes foram escolhidos segundo os fatores sexo, idade e escolaridade, todos moradores antigos e residentes no município.

A coleta e avaliação de dados para a pesquisa se processou nas seguintes etapas:

1) aplicação de um questionário com 10 situações que evidenciavam um contexto específico, sempre contendo duas alternativas de estruturação sentencial para a descrição do evento denotado na situação, uma com o emprego de nós e outra com o emprego de a gente; o entrevistado ouvia a delineação dos contextos e escolhia uma das duas opções de enunciado (com nós ou a gente), sempre de acordo com o uso que ele faz diariamente, em situações de uso oral da língua; 
2) as respostas foram tabuladas e os dados avaliados, levando-se em consideração as variáveis: gênero, idade, escolarização e contexto linguístico (nós/ a gente na posição de sujeito ou de complemento de um verbo, nome ou preposição);

3) com base nos resultados, constitui-se a generalização e a tese principal que buscamos defender neste trabalho.

O texto se estrutura da maneira que segue: na próxima seção, discuto algumas questões teóricas sobre variação linguística e sociolinguística variacionista. $\mathrm{Na}$ seção 3, apresenta-se o constraste entre o pronome nós e a variante inovadora a gente. A seção 4 traz os resultados e análise dos dados, e a seção 5 apresenta as considerações finais da pesquisa.

\section{ALGUMAS QUESTÕES PRÉVIAS}

Mais do que analisar a língua em sua estrutura, vale analisar a língua como um objeto vivo, cujos usos podem legitimar algumas construções e pôr à parte outras. Trago nas seções a seguir algumas questões teóricas de relevância para a discussão que se instaura no presente artigo.

\subsection{VARIAÇÃO E SOCIOLINGUÍSTICA VARIACIONISTA}

As mudanças e variações na língua ficam evidentes, por exemplo, quando que nos deparamos com dificuldades na leitura de textos antigos e na complexidade de compreensão entre falantes de um mesmo país, mas de regiões diferentes; isso pode ser uma evidência de que a língua se adapta segundo situações de fala específicas, conforme ambiente e contexto de uso, além de evoluir através dos tempos.

Segundo Cezario e Votre (2008, p. 144 - 145), o estudo dos processos de variação e mudança permite estabelecer três tipos básicos de variação linguística: a variação de registro, referente ao grau de formalidade do meio usado para comunicação; a variação regional, associada às distâncias espaciais entre cidades, estados, regiões ou países; e variação social, base para nossa pesquisa, que está 
associada a diferenças entre grupos socioeconômicos, relacionadas a variáveis que iremos explorar como faixa etária, grau de escolaridade, etc.

A alternância entre as variantes acontece em um "campo de batalha" e uma irá se sobressair sobre à outra; a ideia aqui é: não há guerra sem adversários, e não há variação sem variantes (Tarallo, 1994); resta ao pesquisador conhecer cada uma dessas variantes profundamente, para que possa ter em mãos argumentos suficientes para conhecer a solução do "caos" linguístico, qual ambiente é mais propício para utilização de uma das variantes, e o que é determinante para o falante quando da escolha de umas delas. Nas palavras de Tarallo (1994):

É somente a partir do perfil individual das variantes que você poderá explorar as armas de que cada uma dispõe, bem como avaliar os contextos mais favoráveis à derrota de uma e à vitória de outra. $A$ essa descrição detalhada das variantes daremos o nome de envelope de variação (TARALLO, 1994, p. 33).

Como descreveu Tarallo, uma percepção do envelope consiste na descrição detalhada das variantes e de quais fatores motivam a escolha de uma delas. Por exemplo, no português falado ou escrito, temos a ocorrência da variação na marcação do plural no sintagma nominal, correspondendo a duas variantes linguísticas: uma com a presença do segmento fônico /s/ e outra sem segmento (Tarallo, 1994):

A essa variável correspondem duas variantes linguísticas, as adversárias do campo de batalha da variação: a variante (1) é a presença do segmento fônico /s/, e a variante (2), em contrapartida, é a ausência desse segmento, ou seja, a forma "zero" (TARALLO, 1994, p. 08).

Assim como a ocorrência da variação no registro de número, as variantes nós e a gente estão em constante "batalha" pelas escolhas dos falantes seja na língua oral, seja na língua escrita e, por essa razão, precisam ser enfocadas e avaliadas. 


\subsection{SOCIOLINGUÍSTICA VARIACIONISTA: ABORDAGEM LABOVIANA.}

A sociolinguística é a ciência que estuda a relação entre língua e sociedade; não há como dissociar esses dois conceitos quando se pesquisa as mudanças sofridas pela língua em determinado contexto. A língua é uma instituição social; portanto, não podemos investigar sua mutação de maneira isolada, autônoma; a cultura e a história dos falantes são fatores a serem estudados para se chegar a respostas sobre a sincronia e diacronia da língua que eles falam.

O americano William Labov, na década de 1960, foi quem iniciou o método de pesquisa adotado neste trabalho conhecido como "sociolinguística quantitativa", "sociolinguística variacionista", ou ainda "teoria da evolução", influenciado por outros modelos de investigação do passado, "trata-se de um modelo teórico-metodológico que assume o "caos" linguístico como objeto de estudo (Tarallo, 1994, p.6)".

A sociolinguística quantitativa trabalha com base na coleta de dados dos falantes em situações reais de fala com o objetivo de analisar o fenômeno da variação baseando-se em pressupostos teóricos que permitem ver a regularidade de possíveis "erros" cometidos pelos falantes, causando um caos na comunicação diária (Cezario e Votre, 2008).

A análise dos dados é feita de acordo com alguns quesitos pré-determinados, segundo Labov, em cinco grandes dimensões: fatores universais limitadores de mudança, que têm influência de fatores sociais e linguísticos; o encaixamento das alterações no sistema linguístico e social da comunidade; a avaliação das mudanças; a transição e a implementação das mudanças que vão garantir o estudo a respeito da língua; saber por que ocorre em determinado evento ou contexto e se acontece de maneira sincrônica ou diacrônica.

O ponto de partida para pesquisa sociolinguística é o objeto de estudo. Através da delimitação do objeto, os pesquisadores podem construir um modelo teórico metodológico e, a partir daí, criar meios de investigar as ocorrências da língua falada em situações naturais e espontâneas para explicar o fenômeno da linguagem.

O pesquisador deve recolher o maior número de dados possíveis para traçar um diagnóstico e averiguar as possíveis variações ou mudanças em curso, ou seja, as variações estáveis em que o falante seleciona o tipo de variante a ser usada de acordo com o contexto e com a situação a que ele se encontra exposto. Como 
exemplo podemos citar o uso de determinadas variantes no convívio familiar, diferentemente das usadas no local de trabalho; portanto, nesse caso temos uma variação estável, relativamente controlada pelo falante.

A mudança em curso é outro caminho da língua; nesse caso, o pesquisador investiga uma possível mudança que está ocorrendo no vernáculo. Aqui o estudo tem que ser analisado de maneira a contrastar dados mais antigos ou entre falantes com diferenças de idade. Esse contraste pode responder a questões como o uso de um determinado vocábulo pelos mais novos, enquanto que os mais velhos não estão praticando, o que gera competição com aumento do uso de uma delas.

\subsection{GRAMATICALIZAÇÃO}

Os estudos sobre variação linguística apontam o processo chamado gramaticalização como um instrumento poderoso que pode causar variação e mudança nas línguas, em função do uso. Entende-se por gramaticalização o processo pelo qual palavras com valor lexical (substantivos, verbos, adjetivos) tranformam-se em palavras de valor gramatical (preposições, afixos, pronomes), num arranjo motivado por um processo de encaixamento no sistema linguístico. A continuidade e a permanência da gramaticalização ocorre em parte em função do termo que sofre alteração, e também - e principalmente - devido a mudanças simultâneas que estão ocorrendo na língua no momento que sofre a transformação.

Segundo Lopes (2004), a gramaticalização possui caráter permanente e contínuo, o que pressupõe a coexistência tanto de valores mais novos quanto de valores mais antigos, mantendo as propriedades lexicais nas formas gramaticalizadas, ou seja, a expressão que passa por um processo de gramaticalização leva consigo traços e significados da forma lexical.

Quando o assunto é a dupla nós $\mathrm{X}$ a gente, na gramaticalização de gente (substantivo) para a gente (pronome) o novo item mantém algumas propriedades, a forma gramaticalizada mantém do substantivo um traço de $3^{\text {a }}$ pessoa, embora semanticamente o novo pronome a gente invoque a existência de mais uma pessoa no discurso, $E u$ + alguém, mesmo o verbo concordando com a $3^{\text {a }}$ pessoa do singular é possível constatar mais uma pessoa no discurso. 
A continuidade e a permanência da gramaticalização em expressões não ocorrem somente pelo termo que sofre a transformação, mas é devido a mudanças simultâneas que estão ocorrendo na língua em determinado momento, de acordo com Zilles (2007), esse processo chama-se feixe de mudanças inter-relacionadas, devido à dependência dos termos para as mudanças. Borges (2004) propõe que a gramaticalização é um tipo de mudança linguística que está sujeita a certos princípios gerais como a transferência metafórica e metonímica, reduções fonológicas e alterações semânticas.

Segundo Castilho (1997), o aspecto conceitual do termo gramaticalização que melhor define o processo que envolve a mudança referente à forma a gente, tem a seguinte definição:

Entendo por gramaticalização o trajeto empreendido por um item lexical, ao longo do qual ele muda de categoria sintática (=recategorização), recebe propriedades funcionais na sentença, sofre alterações morfológicas, fonológicas e semânticas, deixa de ser uma forma livre, estágio em que pode até mesmo desaparecer, como consequência de uma cristalização externa (CASTILHO, 1997, p.31).

De acordo com a definição de Castilho, gramaticalização seria um processo gradativo onde o termo sofre alterações ao longo de sua trajetória, na qual forças externas referentes à própria estrutura da língua atuam de acordo com diferentes regras das diferentes comunidades, supõe-se que as mudanças sofridas pelo termo estejam relacionadas às características sociais que são próprias dos falantes, como idade, sexo, classe social e etc.

\section{DO CONTRASTE NÓS / A GENTE: QUESTÕES TEÓRICAS}

De acordo com Zilles (2007), o uso de a gente na posição de sujeito teve um grande crescimento nos anos 70 e 90, o que nos faz notar o constante aumento do seu uso como primeira pessoa do plural, em substituição de nós, sem distinção de classe ou nicho. O que acontece hoje é a gramaticalização da expressão a gente, motivado por um processo de encaixamento no sistema linguístico. 
As gramáticas tradicionais também abordam o tema. Bechara (2006) trata o termo a gente como pronome e diz que este é usado em linguagem informal, em ambientes onde o falante não se preocupa com formalidades. Azeredo (2012) conceitua os pronomes pessoais como o conjunto de indivíduos nos quais o eu se encontra, trata ainda nós/a gente na parte dedicada aos pronomes, porém apenas descreve o pronome nós. Sobre a expressão o autor comenta:

Os brasileiros empregam em geral a forma a gente, especialmente na língua falada semiformal e informal, como equivalente de nós, seja com um valor genérico/indeterminado (como o do pronome se: não se sabe / a gente não sabe), seja para a referência dêitica situacional identificada (AZEREDO, 2012, p. 176).

Segundo Azeredo (2012), o falante usa o pronome a gente para referenciar uma pessoa indeterminada ou genérica, por isso é mais comumente usado do que o pronome nós; a língua falada de maneira informal em ambientes propícios, está diretamente relacionada ao uso do pronome a gente, o que pode também significar intimidade entre as pessoas do discurso.

Cezario e Votre (2008) afirmam que as duas formas são aceitas pelos falantes em geral, mas o que os diferencia é o contexto em que cada uma é utilizada: o pronome nós em situações mais formais e a forma inovadora a gente em contextos mais coloquiais. Os autores ainda citam que além da forma a gente ser usada com verbos na terceira pessoa do singular, e nós com a primeira pessoa do plural, existem ainda formas mais estigmatizadas como: "nós fala" e "a gente falamos" onde geraria mais questionamentos quanto ao uso das variantes.

O foco do trabalho será avaliar a escolha de uma das variantes pelos moradores considerando os fatores linguísticos e extralinguísticos já citados, e avaliar em qual estágio se encontra o processo, se se trata de uma mudança em curso, ou de formas em variação.

\section{ANÁLISE DOS DADOS}

A escolha por uma das variantes aqui pesquisadas sofre diversas influências que estão fora do contingenciamento linguístico; idade, sexo, nível socioeconômico, 
escolaridade e contexto sintático, podem determinar ou pelo menos indicar a escolha. Suponha que a fala menos monitorada de conversas informais tendam a fazer uso da variante a gente, enquanto o pronome nós é usado para indicar prestígio e conhecimento da língua, podemos dizer que o fator ambiente está influenciando na escolha da variante.

Faixa etária e sexo/(gênero) também são variáveis extralinguísticas que talvez possam nos mostrar qual das variantes está em maior uso, se crianças e jovens falam do mesmo modo dos mais velhos, como isso é determinante para uma mudança em curso ou para a confirmação de uma variável? Em relação ao sexo, podemos observar o que leva homens e mulheres preterirem uma delas, quem usa mais e qual as regras para seu uso? Essas e outras perguntas irão nortear esta pesquisa. Vejamos a seguir a ocorrência das variáveis no município goiano. No gráfico 1 temos a visão geral das ocorrências:

\section{Gráfico 1: nós e a gente na cidade de Luziânia}

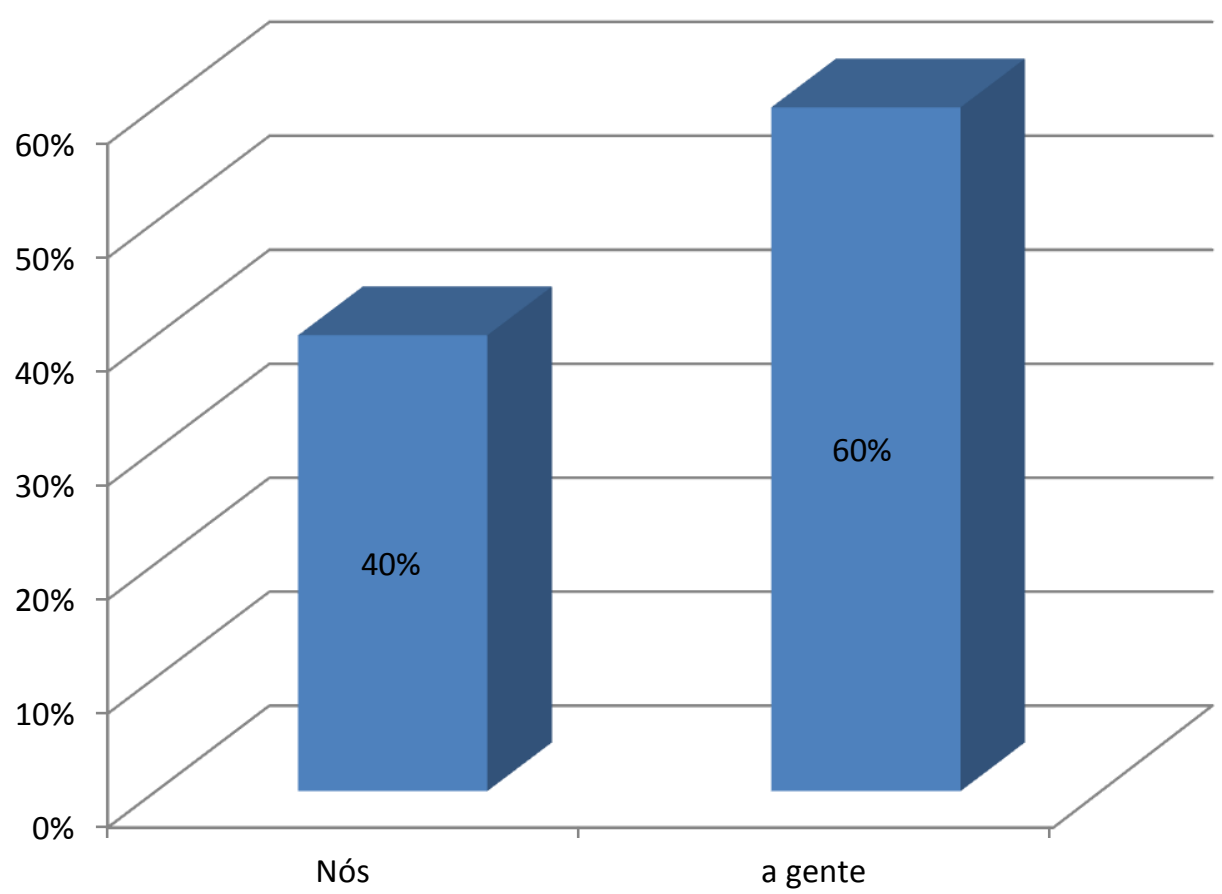


De acordo com o gráfico 1, observa-se a escolha da variante a gente como preterida entre os moradores de Luziânia, mas o número não tão expressivo mostra que a mudança em curso levantada como hipótese dessa pesquisa ainda não se consolidou; existe uma variação linguística em curso e, ao que tudo indica, o ambiente, mais formal ou menos formal, irá influenciar na escolha de uma das variantes haja vista que $40 \%$ da população faz uso do pronome nós em situações de fala, não podemos afirmar uma mudança em curso.

Agora vejamos como ocorre o uso da variante a gente segundo os fatores sociais sexo/(gênero) e faixa etária respectivamente, analisados a fim de constatar uma possível substituição do pronome nós pela variante a gente, ou para que se constate que se trata apenas da ocorrência de variação.

\section{Gráfico 1: nós e a gente segundo o fator social sexo}

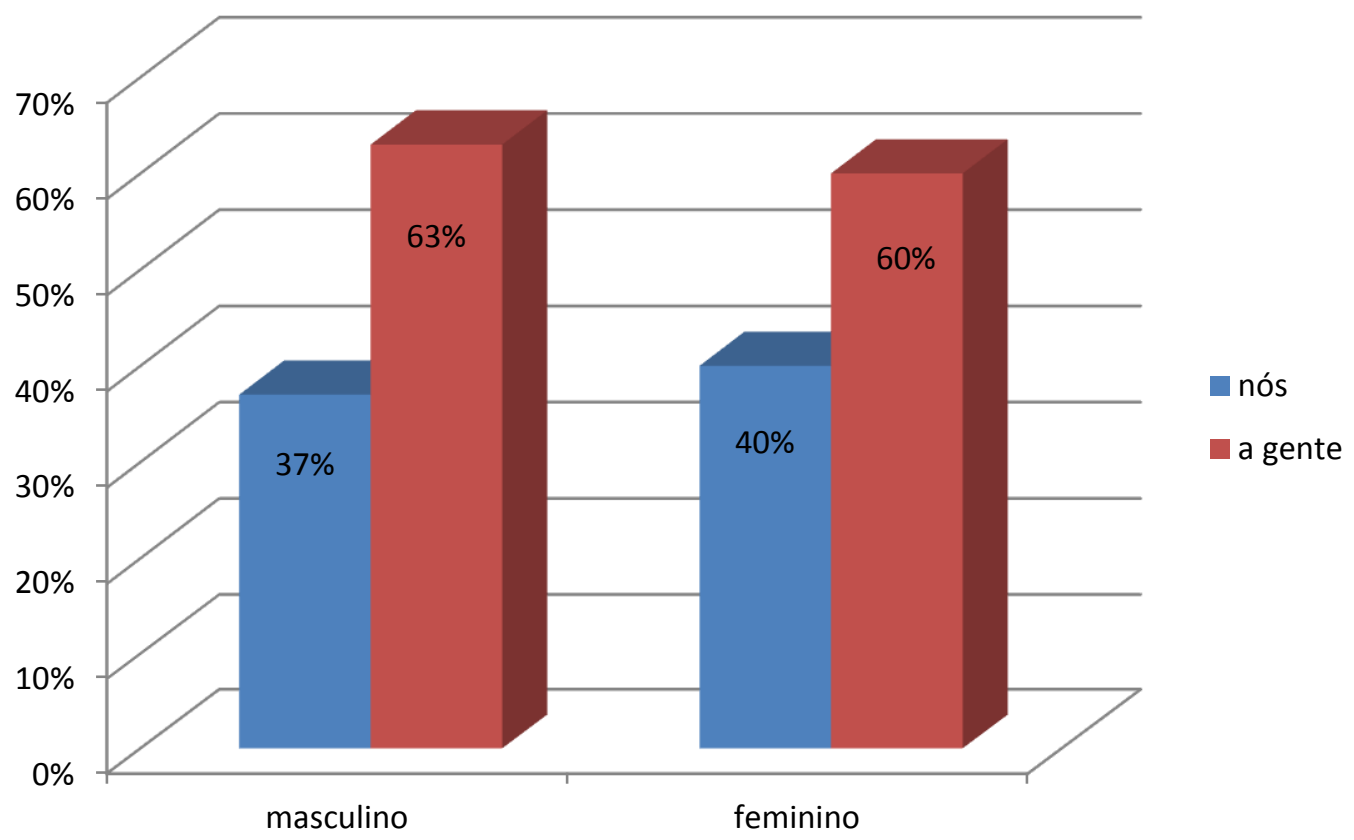

Como podemos observar, o variável social sexo/(gênero) demonstra equilíbrio entre o uso das variantes. O uso de a gente por homens é de $63 \%$, e entre as mulheres é algo em torno de $60 \%$; portanto não existem diferenças relevantes entre os sexos masculino e feminino, o que nos leva a concluir que 0 
fator sexo não é determinante na escolha de uma das variantes. A diferença entre nós e a gente em ambos os sexos praticamente repetem os números obtidos no Gráfico 1 com a visão geral do fenômeno.

\section{Gráfico 3: nós e a gente segundo a faixa etária}

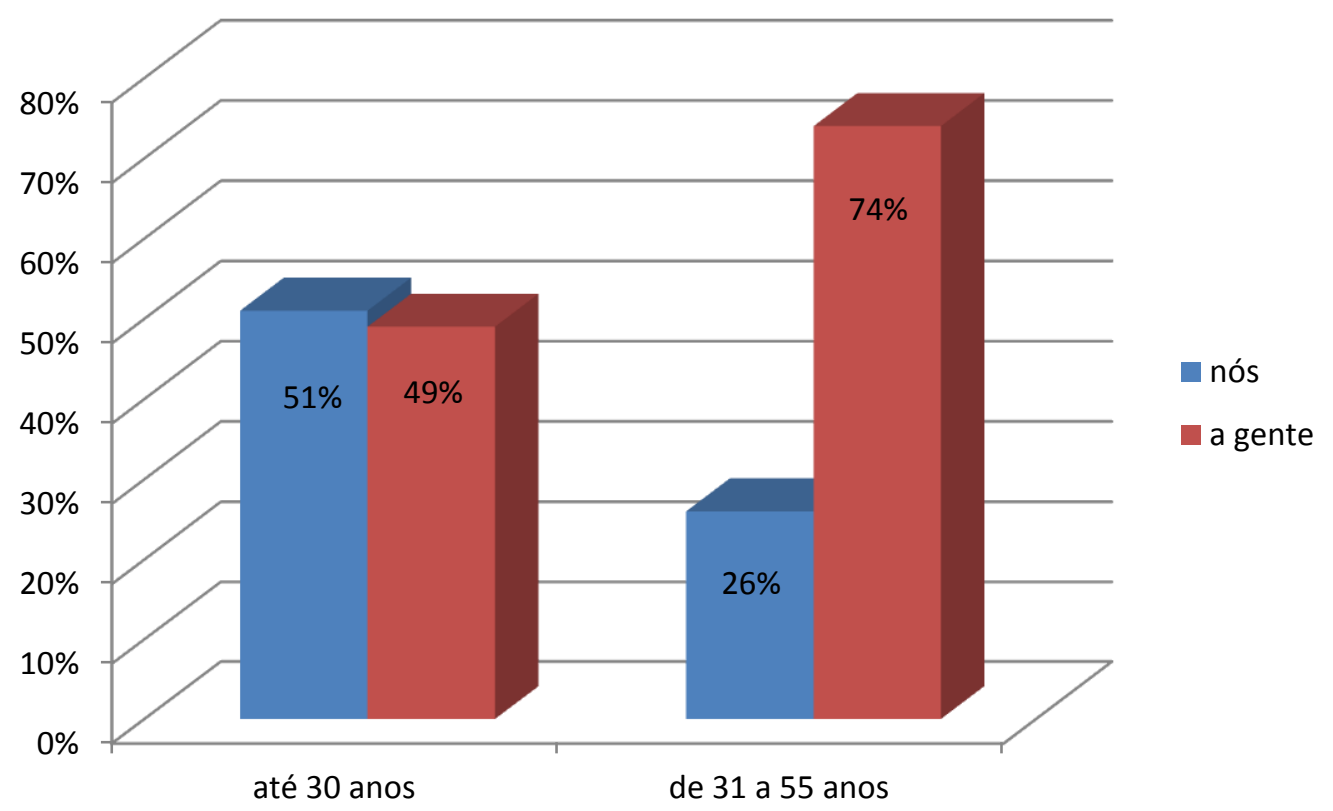

Enquanto em grande parte do país as pesquisas indicam maior ocorrência do uso de a gente entre os mais jovens, em Luziânia, temos o contrário: na faixa etária de 31 a 55 anos, $74 \%$ da população faz uso da variante a gente, enquanto na faixa etária até os 30 anos não existe uma diferença considerável entre os usos de nós e a gente.

Esses resultados nos mostram uma variação linguística em curso entre os mais idosos. Por se tratar de cidade do interior, a preferência pela variante a gente é justificável pela menor formalidade requerida para seu uso; a população mais experiente não monitora tanto a fala como os mais jovens, o que representa o equilíbrio da faixa etária até os 30 anos, na qual temos pessoas mais jovens e consequentemente em contato com ambientes mais formais como a escola, faculdade e trabalho, locais onde teoricamente se exige a norma urbana de prestígio. 
O gráfico 4, que quantifica o uso das variantes segundo a escolaridade, pode elucidar e nos ajudar a entender melhor os resultados do gráfico 3.

\section{Gráfico 4: nós e a gente segundo escolaridade}

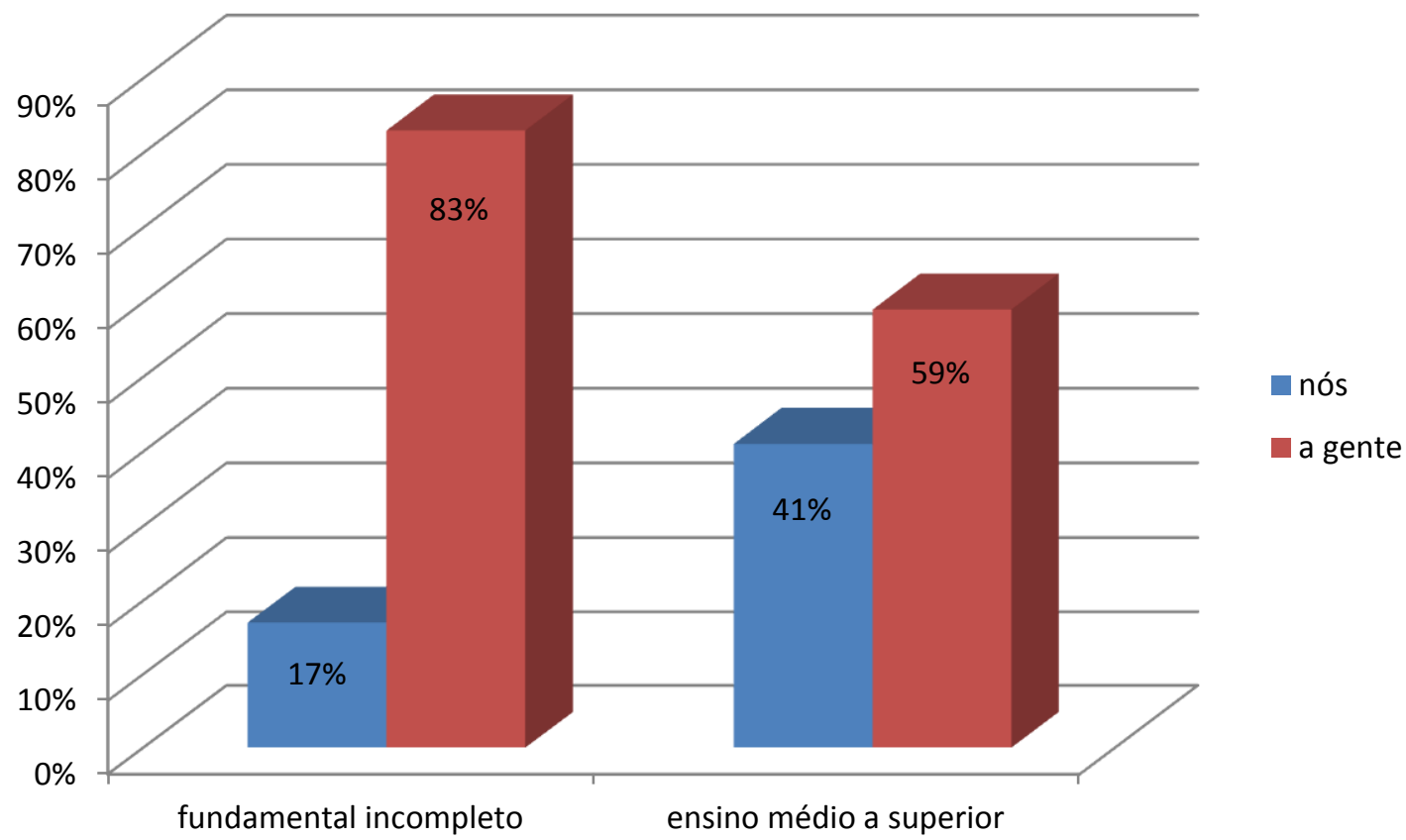

Vemos aqui os resultados da variação entre os menos escolarizados e os mais escolarizados. Em se tratando de cidade do interior, os pais, pessoas mais idosas, também fazem parte das estatísticas dos moradores com menos escolaridade, são moradores que não tiveram tanto contato com ambientes mais formais, o que nos revela os números do gráfico. Em contrapartida, os filhos desses moradores, portanto de menor idade, são privilegiados com condições melhores para frequentar escola, faculdade, ter acesso a melhores empregos, ambientes que ainda exigem mais formalidade e consequentemente o uso do pronome nós, ainda que a diferença entre os mais escolarizados nos indique a força do termo a gente, influenciando uma variação em curso. 


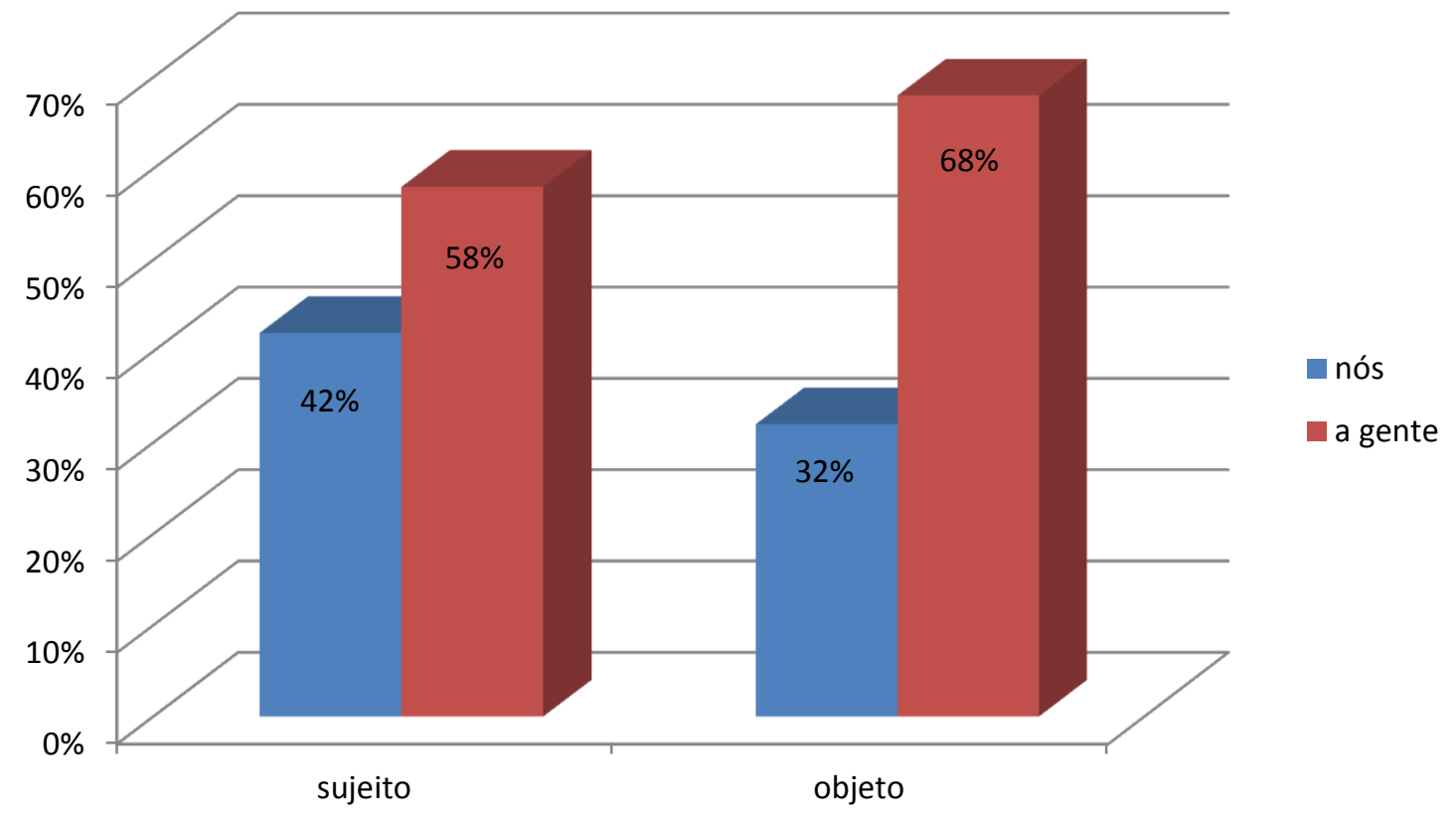

O gráfico 5 nos revela o uso das variantes segundo o contexto sintático. $\mathrm{Na}$ posição de sujeito, a diferença não é tão expressiva; em compensação, na posição de objeto, os falantes optam pela variante a gente. Como foi levantado no início da pesquisa, o português falado no Brasil parece estar no meio do caminho entre deixar a posição de sujeito vazia em certos contextos, como em (4), facilitando a escolha do pronome nós, o que não acontece em outros casos como em (5). Com isso, o falante opta pela variante nós na posição de sujeito pela não necessidade de um sujeito explícito.

O que acontece no interior de Goiás é algo incomum. Conforme Duarte e Kato (2014), o português brasileiro vem mostrando de forma geral um declínio na ocorrência de sujeito nulo formado pelo pronome nós, e a preferência pelo sujeito explícito a gente. Em Luziânia, ocorre um equilíbrio entre as variantes, nós (42\%) e a gente (58\%), em posição de sujeito, demonstrando uma harmonia entre as formas em oposição ao que foi constatado de maneira geral no português do Brasil. Já na posição de objeto, o número expressivo de a gente reflete uma facilidade na colocação pronominal:

(7) Ele vai ao cinema com a gente.

(8) Ele vai ao cinema conosco. 
Em (8) a frase exige um ambiente mais formal, enquanto em (7) a fala flui de forma mais natural, e por isso a escolha da variante a gente na posição de objeto mostra-se bem mais frequente.

\section{CONSIDERAÇÕES FINAIS}

De modo geral, podemos concluir que a escolha por uma das variantes (nós/a gente) está condicionada na comunidade de fala de Luziânia, interior de Goiás, por fatores extralinguísticos como idade e escolaridade, e por fatores linguísticos como posição sintática. A variável sexo não teve diferença expressiva; tanto homens quanto mulheres utilizam as variantes de maneira igual. Os resultados da pesquisa corroboram a hipótese do uso da variante a gente como um pronome inovador, apesar de não serem claros a respeito de uma mudança linguística; por isso fala-se em apenas uma variação linguística em curso, até porque o assunto necessita de acompanhamento por um período maior de tempo para ser definido como mudança, mas como variação o pronome já está consolidado.

Já nos resultados quanto à variável idade, constatou-se algo diferente de outras pesquisas desenvolvidas no resto do país, segundo as quais ocorre a prevalência da forma inovadora a gente na fala dos mais novos, e a do pronome nós na fala dos mais velhos; em Luziânia, como vimos, os resultados evidenciam exatamente o contrário. Tudo leva a crer que isso se deva à diferença de escolaridade entre mais novos e mais velhos, considerando que esses últimos não tiveram acesso fácil à escolarização, diferentemente de seus filhos e netos, os quais acabam por monitorar mais a fala, em razão de terem de a empregar em contextos mais formais de uso. A variável escolaridade nos revelou (em corroboração aos muitos estudos em variação) que os falantes mais escolarizados optam pela forma consagrada nós.

O último tópico da pesquisa nos revela uma diferença não muito expressiva entre as variantes na posição de sujeito, e uma diferença mais considerável na posição de objeto. Observou-se que em situações de monitoramento de fala os falantes optam pela variante que indica mais prestígio, nós; em contrapartida, como 
mostra o resultado da pesquisa, os falantes preferem em sua maioria o uso da variante a gente em discurso menos formal e com fala sem monitoramento.

Estudos mais detalhados do caso em questão na fala de Luziânia ficam para investigações futuras.

\section{REFERÊNCIAS}

A gramaticalização de a gente em português em tempo real de longa e de curta duração: retenção e mudança na especificidade dos traços intrínsecos.

Florianópolis: Fórum Linguístico. v. 4, n. 1 (47-80), julho de 2007.

AZEREDO, José Carlos de. Gramática Houaiss da Língua Portuguesa. São Paulo: Publifolha, 2012.

BECHARA, Evanildo. Moderna gramática portuguesa / Evanildo Bechara. - 37. ed. rev., ampl. e atual. conforme o novo Acordo Ortográfico. - Rio de Janeiro : Nova Fronteira, 2009.

BORGES, Paulo R. S. A pessoalização do pronome a gente sob a perspectiva da Teoria da Enunciação de Émile Benveniste. Letras de Hoje. Porto Alegre, v. 39, n. 4, p. 163-172, dezembro, 2004.

BRUSTOLIN, Ana Kelly Borba da Silva. Análise da Variação no uso de "nós" e "a gente". Florianópolis, 2009.

CASTILHO, Ataliba T. de. A gramaticalização. Estudos lingüísticos e literários, 19: 25-64. Salvador: Programa de Pós-graduação em Letras e Lingüística da UFBA, 1997.

CEZÁRIO, Maria Maura; VOTRE, Sebastião; COSTA, Marcos Antônio. In: MARTELOTTA, Mário Eduardo (Org.). Manual de linguística. São Paulo: Editora Contexto, 2008, p. 141-155.

DUARTE, ME. A representação dos sujeitos de "referência estendida": um estudo diacrônico. In LOBO, T., CARNEIRO, Z., SOLEDADE, J., ALMEIDA, A., and RIBEIRO, S., orgs. Rosae: linguística histórica, história das línguas e outras histórias [online]. Salvador: EDUFBA, 2012, pp. 123-136. ISBN 978-85-232-1230-8. Available from SciELO Books <http://books.scielo.org>. 
KATO, Mary A.; DUARTE, M. E. L. (2014). Restrições na distribuição de sujeitos nulos no Português Brasileiro. In: VEREDAS on-line - Sintaxe das Línguas

Brasileiras 2014/1 - ISSN: 1982-2243. Programa de Pós-Graduação em Linguística, Universidade Federal de Juiz de Fora.

LOPES, Célia Regina dos Santos. A gramaticalização de a gente em português em tempo real de longa e de curta duração: retenção e mudança na especificação dos traços intrínsecos. Fórum Linguístico, v. 4, №1. Florianópolis, julho de 2004.

LOPES, Célia Regina dos Santos. Nós e a gente no português falado culto do Brasil. DELTA, vol. 14, ํo 2, São Paulo: EDUC:1998. p. 405-422.

TARALLO, F. A pesquisa sociolinguística. São Paulo: Ática, 1994.

ZILLES, Ana M. S. O que a fala e a escrita nos dizem sobre a avaliação social do uso de a gente? Letras de Hoje.

Porto Alegre, v. 42, n. 2, p. 27-44, junho, 2007. 